\title{
Mechanical Stress Analysis of a 600MW Supercritical Boi- ler Superheater Outlet Header
}

\author{
Dongyi Li, Zhongguang Fu, Qiang Zhang, Ting He \\ School of Energy,Power and Mechanical Engineering;North China Electric Power University;Beijing,China \\ Email: aiolos-u@163.com
}

Received 2013

\begin{abstract}
The mechanical stress distribution and the stress concentrations of the superheater outlet header of a 600MW supercritical boiler were analyzed by the finite element method. The results showed that the stress concentrated at the inside conjunction area between the pipe and the header cylinder , and the value of the maximum mechanical stress concentration factor is 2.51 .
\end{abstract}

Keywords: Superheater Outlet header; Finite Element Method; Stress Concentration

\section{Introduction}

With the development of economy and the rapid increase of electricity demand, large-capacity high-parameter thermal power generating unit takes part in the peak load operation. Since the boiler load changes greatly during the peak load operating process, the stress of the bearing pressure parts changes rapidly. Because of that, the stress of the boiler load section changes drastically which eventually shorten the original operating time very much $1,2]$. Therefore, the stress analysis of the bearing components becomes essential for operating the power plant safely and economically.

The total stress is mainly impacted by the internal pressure on the basis of previous studies[3,4].This paper takes a superheater outlet header of a $600 \mathrm{MW}$ boiler as the research object to analyze the distribution and variation law of mechanical stress with the finite element analysis software-ANSYS. Besides, the pressure data during the process of load pick-up is passed as boundary conditions.

\section{Model and Boundary Conditions}

\subsection{Structure of Header}

Figure 1 shows the structure of the superheater outlet header of a 600MW supercritical boiler.

This research considers the header as a thick walled cylinder which diameter and wall thickness are $635 \mathrm{~mm}$ and $136 \mathrm{~mm}$. On the cylinder, 68 rows of nozzles are evenly distributed with $304.8 \mathrm{~mm}$ between each two rows. The diameter and wall thickness for each nozzle are $45 \mathrm{~mm}$ and $11 \mathrm{~mm}$. The metal material of the header is
T92/P92[5,6] .

Three hypotheses are proposed for the following analysis: (1) all physical parameters of the cylinder are isotropic; (2) a half part of the cylinder and the inserted nozzles was taken by the model because of the symmetrical structure of the cylinder; (3) One nozzle was randomly taken by the model because all nozzles are evenly distributed on the whole cylinder. The model which contains 52994 units and 79843 nods is analyzed by an algorithm of free mesh SOLID98 element in this research. Check the model on Figure 2.

\subsection{Load and boundary conditions}

The right cross-section(B-surface) on $\mathrm{Y}$-axis shifting and the two longitudinal section(A-surface) on $\mathrm{X}$-axis shifting needs to be constrained. At the same time, restrain the shifting of the Z-axis on a critical point-D. When loading the internal-pressure on the inner wall, the tensile load also needs to be loaded on the left cross-section and five nozzle cross-section surfaces in the meantime. The equations to calculate the tensile load are shown below [7].
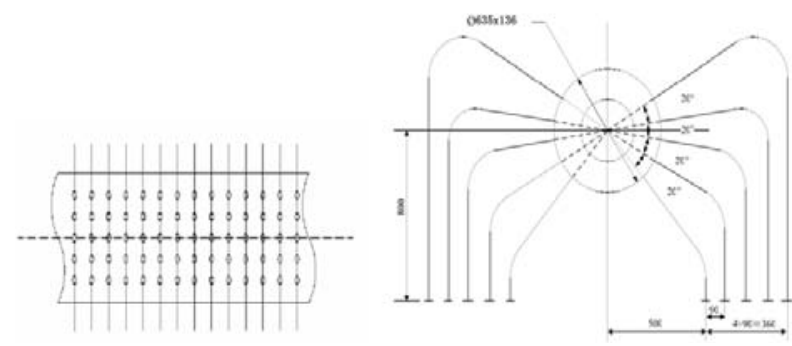

Figure 1. The structure of header. 

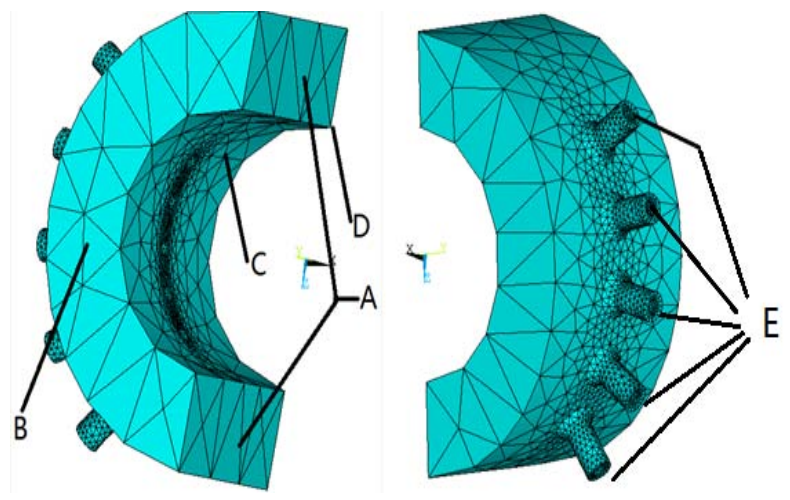

Figure 2. The model and the grid division.

$$
\begin{gathered}
P_{c}=P_{i} \frac{d_{i}^{2}}{d_{o}^{2}-d_{i}^{2}} \\
P_{D}=P_{i} \frac{D_{i}^{2}}{D_{o}^{2}-D_{i}^{2}}
\end{gathered}
$$

Where $\mathrm{PC}=$ cylinder end cross-section uniform tension,mm; $\mathrm{PD}=$ nozzles end cross-section uniform tension, $\mathrm{mm} ; \mathrm{Pi}=$ internal pressure, $\mathrm{MPa} ; \mathrm{do}=$ nozzles outer diameter,mm;di=nozzles inner diameter,mm; Do = cylinder outer diameter, mm; Di = cylinder inner diameter,mm.

The data of load that used for analysis are the actual operating data in a power plant. The changing path of the internal pressure is shown in Figure 3.

\section{Results and Discussion}

\subsection{Distribution of Mechanical Stress}

Figure 4 shows the distribution of mechanical stress.As shown in Figure 4, mechanical stress changed greatly at the inside conjunction area between the pipe and the header cylinder when it changed very little at the area which far from the intersecting line area. The phenomenon of stress centralization at the intersecting line area is in evidence. The stress at the area far from the intersecting line area can be considered as the membrane stress of the cylinder. It can be calculated with the follow equation[8]:

$$
\sigma=\frac{P\left(D_{i}+S\right)}{2 S}
$$

where $\mathrm{P}=$ internal pressure, $\mathrm{MPa}$; $\mathrm{Di}=$ cylinder inner diameter,mm; $\mathrm{S}=$ wall thickness, $\mathrm{mm}$. Comparison of the ANSYS analysis to the theoretic calculation is shown in Figure 5. Two results are basically the same. According to the comparison, the reliability of ANSYS is verified.

\subsection{Maximum Stress Point}

During the running process, the maximum stress ap- peared mainly at point-N as shown in Figure 6. The point is on the intersecting line.The variation of mechanical stress at point-N shows in Figure 7.

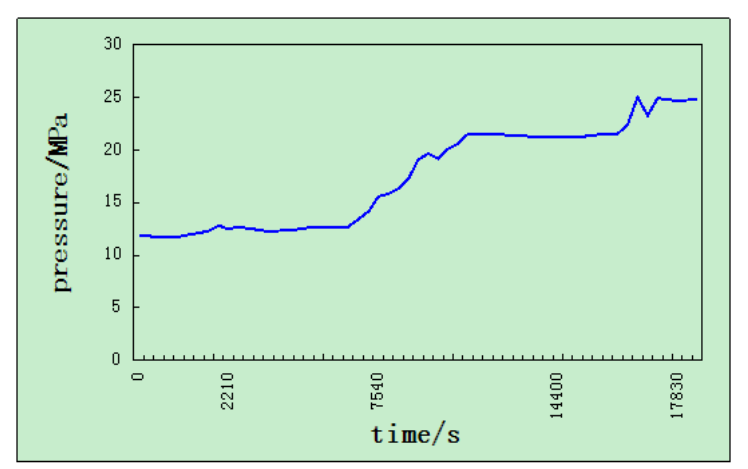

Figure 3. Pressure change curve in pick-up load process.
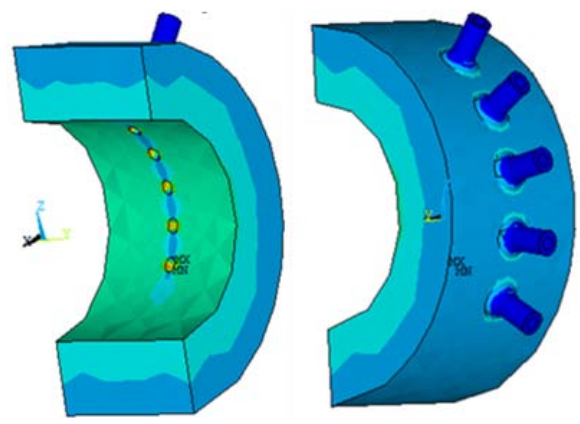

Figure 4. Cloud picture of mechanical stress.

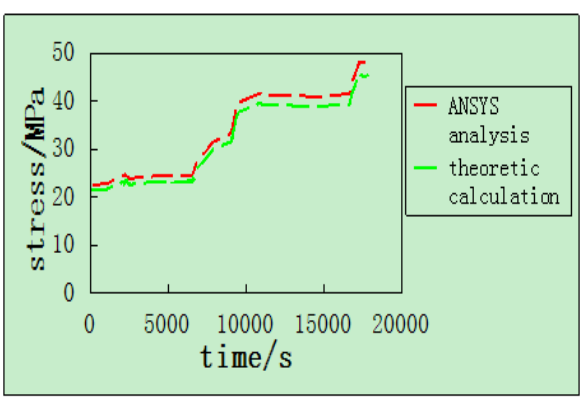

Figure 5. Comparison of the ANSYS analysis to the theoretic calculation.

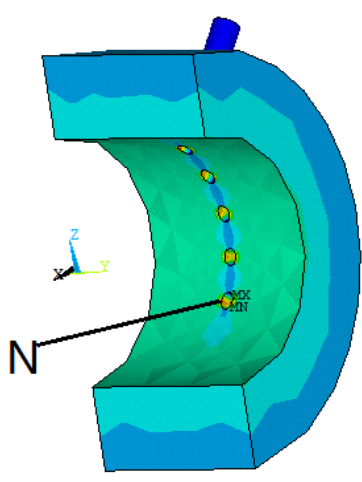

Figure 6. Position of point-N. 


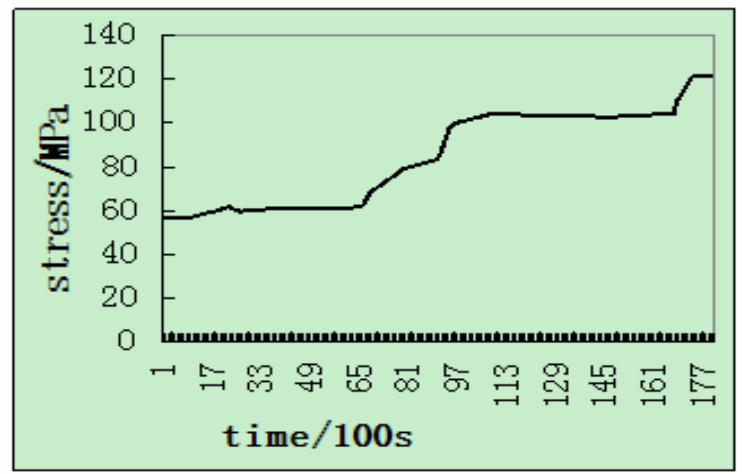

Figure 7. Variation of stress at point-N.

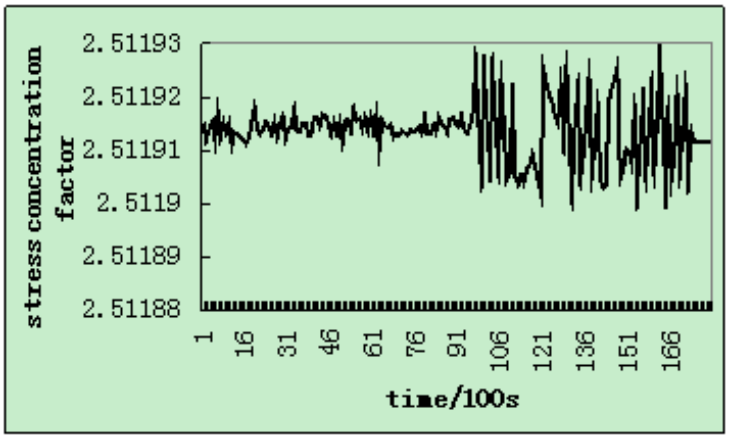

Figure 8. Changing curve of stress concentration factor.

Impacted by the internal pressure, the mechanical stress and the internal pressure are sharing the similar changing tendency. The value of mechanical stress is varying from 56.61MPa to $121.01 \mathrm{MPa}$.

\subsection{Stress Concentration Factor}

The mechanical stress concentration factor is independent of running condition[7]. The stress on the study area is directly proportional to the value of the internal pressure. Define stress concentration factor as follow[9]:

$$
k=\frac{\sigma_{\text {max }}}{\sigma}
$$

where $\sigma_{\max }=$ maximum stress. The changing curve of the stress concentration factor during the process of load pick-up at point-N is shown in Figure 8.

Based on above computations, in the later period of the load pick-up process, the stress concentration factor with its value 2.51 can be considered keeping stable during the whole process because of the tiny changes on the amplitude of the factor.

\section{Conclusion}

- Refers to the computations, the phenomenon of stress centralization at the inside conjunction area between the pipe and the header cylinder is obvious. Far from the intersecting line area changes less in stress; it can be considered as the membrane stress of the cylinder.

- The maximum stress is distributed mainly at point-N which is focused on the intersecting line. According to the numerical calculation, the stress concentration factor of point- $\mathrm{N}$ is 2.51 .

- These analysis results, especially the stress concentration factor, can be used in life expenditure on-line monitoring system in following research.

\section{REFERENCES}

[1] D. Q. ZHANG, S. J. YANG, G. Z. LIU and G. C. Zhang, "Fatigue Life Assessment of Plant Drum in service," Shandong Electric Power, vol. 2, NO. 6, 1997, pp. 19-21+25.

[2] Y. G. PEI, Y. F. SHEN, T. L. YANG, Z. D. Cao, J. Wu, S. X. Zhuang and H. D. Wang, "Management System of Boiler Drum s Fatigue Life," Journal of Xi An Jiaotong University, vol. 5, NO. 16, 1999, pp. 64-67.

[3] L. B. HE, "Service Life Analysis of The High Temperature Superheater Outlet Header in a 600MW Supercritical Boiler," Master, Thesis, North China Electric Power University, Beijing, 2011.

[4] Q. Z. YIN, J. S. XIAO, A. L. Jiang, Y. P. Chen and Z. L. Zhao, "Finite Element Analysis of Three Dimensional Transient Stress in 300MW Boiler Drum," Journal of Wuhan University of Technology(Transportation Science \& Engineering), Vol. 1, No. 17, 2007, pp.60-62+69.

[5] Vallourec \& Mannesmann Tubes. "T92/P92 steel Handbook," In: (Ultra-) supercritical boiler steel and welding technical symposium, 2005, pp. 285-304.

[6] Z. W. SHI, "Numerical simulation of temperature field for T92/12Cr1MoV dissimilar steel welding," Mechanical research and Application, Vol. 4, No. 41, 2010, pp. 99-101+104.

[7] Z. J. WANG, "Boiler structure finite element analysis," Chemical Industry Press, Beijing, 2005.

[8] T. Liu, "Life Estimation and On-line Monitoring for Pressurte-bearing Part of Utility Bolier," Ph.D. Thesis, North China Electric Power University, Beijing, China 2007.

[9] D. B. WANG, X. L. WEI, S. XIANG, C. X. Guo, J. X. $\mathrm{Wu}$, "Stress analysis and design for tangential opening tubing connection on pressure vessels," China Petroleum Machinery, Vol. 4, No. 2, 2006, pp. 5-7+85. 